\title{
Processing of refractory gold sulphide carbon- bearing ores by means of their pre-oxidation with water-and-gas emulsions prepared in electrochemical and photochemical reactors
}

\author{
Artur Sekisov ${ }^{1 *}$, Paul Korpi ${ }^{2}$, Anna Rasskazova ${ }^{1}$, Natalia Litvinova ${ }^{1}$ and Tatiana \\ Konareva $^{1}$ \\ ${ }^{1}$ Mining Institute of Far eastern branch of Russian Academy of Sciences, Khabarovsk, Russia. \\ ${ }^{2}$ Limited Liability Corporation "IG Copper LLC", Russia.
}

\begin{abstract}
In connection with the depletion of mineral resources base of gold, the engagement of refractory ores reserves in the processing becomes a necessary condition to stabilize gold market. Standard methods of processing of refractory sulphide carbon-bearing gold ores and float concentrates extracted from them include pressure oxidation and bacterial oxidation enabling the liberation of dispersive gold and oxidation of carbon having parasitical sorption with further cyanation. The alternative solution of the aforementioned problem is pre-oxidation of refractory ores with water-and-gas emulsions. Theoretical basis for active water-and-gas emulsions formation with the use of electrolytes solutions electrolysis in combination with ultraviolet exposure is stated in the article. Given method of water-and-gas emulsions preparation ensures the formation of active oxidants complex. Gold recovery into pregnant solutions up to 55.7 $73.5 \%$ by chloride scheme was reached in laboratory experiments on samples of sulphide carbon-bearing ore, herewith $18 \%$ was recovered using cyanic solution. Based upon experimental findings, process scheme for combined oxidative preparation of sulphide carbon-bearing ore with dispersive deportment of gold was developed.
\end{abstract}

\section{Introduction}

Sulphide carbon-bearing gold ores, due to the presence of sorption and active particles of organogenous carbon and residual organic compounds causing re-precipitation of gold diluted in the course of leaching with themselves, are characterized by exceptionally low rate of its recovery (as a rule not exceeding 20\%). Gold ores containing carbonaceous matter and sulphidic minerals are generally referred to as double refractory. Extraction of the gold from such ores usually requires an oxidation step to both liberate the ultra-fine gold from the matrix of the sulphides and remove the carbon that preg-robs the dissolved gold. Besides well known pressure oxidation and roasting microwave roasting can be applied to oxidize both the sulphides and the carbonaceous matter [1]. The ability of pyrite

\footnotetext{
* Corresponding author: sekisovag@mail.ru
} 
and chalcopyrite to adsorb gold is a well-known fact. The degree of adsorption onto the ore or the activated carbon is a function of the kinetics of the adsorption process. Copper, silver, zinc, nickel and iron complexes counteract preg-robbing, and serve to stabilise the aurocyanide complex by precipitating prior to gold precipitation. When cyanide or cyanidespecies present in solution, the adsorption onto activated carbon is in preference to the adsorption onto the minerals [2].

Besides, gold may be present in ores of that mineragenic type as bi-element clusters of $\mathrm{Au}-\mathrm{C}$ type as well which is reluctant to cyanation. Formation of AuSx is indicated at the gold surface of double refractory gold ore (sulphide with carbon coatings) in a cyanide medium [3]. For instance, the presence of carbon with graphite structure matrix consisting of ether and thiocarbamide functional groups is established in ores of deposit of Goldstrike, Carlin Trend. It is assumed that carbon not only sorbed gold during ore genesis and retained bonds with it in ores, direct ones as Au-C as well as through Au-S-C $\left(\mathrm{NH}_{2}\right)_{2}$ thiocarbamide functional groups, but formed bi-element cluster compounds with gold in the course of metamorphous process and carbonation.

In connection with the depletion of mineral resources base of gold, the engagement of reserves of such refractory ores in the processing becomes a necessary condition to stabilize gold market.

Currently two process schemes of processing are primarily used to treat refractory sulphide carbon-bearing gold ores or float concentrates extracted from them: scheme with pressure oxidation and bio-oxidation (bacterial oxidation) [4]. [5]. These schemes are applicable only for ores the gold content of which is at least $2.5-3 \mathrm{~g} / \mathrm{t}$. Therefore, the development of alternative technologies for raw and poor sulphide carbon-bearing ores not requiring significant energy costs and reagent consumption is an actual problem in goldmining industry. One of the future solutions for the problem is the use of ozone as oxidant for carbon-bearing ores in gold leaching. This idea was justified as far back as in works of 30 -s - 40-s of XX century by an outstanding Russian scientist and metallurgist, a corresponding member of Academy of Sciences of the USSR - I.N. Plaksin. Detailed study of oxidation with sorptive and active carbon-bearing inclusions of gold ores from Carlin Trend were conducted by American researchers (gold recovery with subsequent cyanation reaches about 90\%) - D.J. Sheiner, R.E. Lindstrom (US Bureau of Mines) in 60-s - 70-s of XX century.

Recent geological exploration demonstrated great interest to Carlin-style mineralization. Gold zones range from 105 to 400 meters in depth, and steepen from flat (10 degrees) to moderate (45 degrees) dips to the east, as they approach the western strand of the NBFZ. Gold is associated with sooty sulfides, silica, carbon, clay, barite, realgar and orpiment in addition to elevated $\mathrm{As}, \mathrm{Hg}, \mathrm{Sb}$ and $\mathrm{Tl}$. High-grade $(>6 \mathrm{~g} / \mathrm{t} \mathrm{Au})$ gold occurs in both the upper and lower gold zones. Some of the best gold intercepts include up to $15 \mathrm{ppm}$ gold content [6]. However, despite the high level of dispersive gold recovery reached with the use of ozone, technical difficulties and high energy costs which exceeded such for electrochlorination method of Carlin-type oxidation prevented this method from being used widely in mining industry. It should be noted that more than 30 years later the research of using ozone as oxidant for carbon-bearing and sulphide ores was successfully carried on in the USA by W.J. Zaleski, W.P. Van Antverp, Ph. A. Lincoln and in the Russian Federation in Moscow Institute of Steel and Alloys (Ph.D. in Engineering Science L.N. Krylova and others) [7]. Nevertheless, the cost of this method of oxidation thus far precludes it from wide use in hydrometallurgy. 


\section{Theoretical basis for preparing active water-and-gas emulsions containing reactive oxygen intermediates}

From the viewpoint of the authors of the article, oxidation of sulphide and carbon-bearing gold ores is practical to conduct not by means of sparging of slurry with ozone-containing gas mixture, but using to this end the solution containing highly active oxidants - the group of peroxide compounds of oxygen with hydrogen (the so-called reactive oxygen intermediates), including, first, hydrated hydroxyl-radical and hydrogen peroxide as well as superoxides of alkali metals. The combination of electrolytes solutions electrolysis with UV exposure ensures the formation of active oxidants complex. In case of UV light exposure within the range of wave lengths of $180-250 \mathrm{~nm}$ of water-and-gas emulsion being formed during electrolysis, highly active oxidants are generated in the volume of gas bubbles, such as: atomic oxygen, $\left(\mathrm{O}^{*-}\right)$ superoxide - radical oil, ozone, $\left(\mathrm{OH}^{*}\right)$ hydroxyl-radical creating, in case of inter-reaction with film water surrounding gas bubbles, radical ion and radicalcontaining clusters. In this case the formation of hydration shells happens around centres of ionization - inoculating ions, radicals and radical ions of hydrogen, oxygen and their compounds, particularly $\mathrm{H}^{+}, \mathrm{OH}^{-}, \mathrm{OH}^{*}, \mathrm{O}^{*-}$ and others [8].

The most active cluster-forming particle is $\mathrm{OH}^{*}$ hydroxyl-radical the oxidation/reduction potential of which reaches the value of $2.8 \mathrm{~V}$ while such for atomic oxygen is $2.42 \mathrm{~V}$ and for ozone $-2.07 \mathrm{~V}$ [9].

From this fact it emerges that not only oxygen atom unpaired electron, but also, to a greater extent, active hydrogen atom or its ionic form - proton as part of hydroxyl-radical - changes structural and energy parameters of electron shells of molecules (atoms) contacting with them.

Since the system consisting of excited oxygen and hydrogen atoms is metastable, it is possible to suggest that hydrogen atom electron occasionally moves to a free orbit of oxygen atom electron shell. Herewith, inner dissociation of $\mathrm{OH}^{*}=\left(\mathrm{O}^{* * *} \mathrm{H}^{+}\right)$occurs in such radical. Hydrogen atom as part of hydroxyl-radical, shifting towards conventional border of electron shell from time to time, becomes an unbound particle - proton with rather high energy. Accordingly, there is a possibility of the fact that its location is not limited only by electron shell of oxygen radical ion associated with it. Therefore, the system $\left(\mathrm{O}^{* *} \mathrm{H}^{+}\right)$may be considered as metastable radical ion pair of $\mathrm{O}^{*}{ }^{*} \mathrm{p}^{+}$as well which has, on one side, the function of a proton acceptor, on the other side - the function of an electron acceptor. $\mathrm{p}^{+}$ primary proton separated from $\mathrm{OH}^{*}$ radical penetrates into electron shell of another nearest water molecule. Thus, hydronium ion $\left(\mathrm{p}^{+}+\mathrm{H}_{2} \mathrm{O}=\mathrm{H}_{3} \mathrm{O}^{+}\right)$emerges. $\mathrm{O}^{*-}$ oxygen radical ion left free polarizes and attracts one of hydrogen atoms from adjoining water molecule with its densed electron shell. Thereat, hydrogen atom being polarized ionizes while moving away from hydrogen radical ion and eventually forced dissociation of water molecule with the formation of $\mathrm{OH}^{-}$hydroxyl ion and $\left(\mathrm{p}^{+}\right)$proton takes place. Free $\left(\mathrm{p}^{+}\right)$proton interreacting with oxygen radical ion reproduces oxygen hydroxyl-radical and, accordingly, $\left(\mathrm{O}^{*}\right.$ ${ }^{*} \mathrm{H}^{+}$) metastable pair. Counter migration in ordered chain of centres of hydronium ions and hydroxyl ions formation leads to their inter-reaction in the end: when a proton penetrates inside an electron shell of hydroxyl ion $\left(\mathrm{H}^{+} \mathrm{H}^{-}\right)$, ion pairs or metastable pairs of hydrogen atoms being joined by $\left(\mathrm{H}^{*}{ }_{(\mathrm{e}+\mathrm{e}-\mathrm{-}} \mathrm{H}^{*}\right)$ electron-positron (exciton) bindings may originate. As a result, local clustering of adjoining water molecules takes place with the formation of at least its dimers: $\mathrm{H}_{3} \mathrm{O}^{+}+\mathrm{OH}^{-}=\mathrm{H}_{4} \mathrm{O}_{2}$. The cycle of dissociation induced by hydroxyl-radicals and association (clustering) of water molecules repeats involving other adjoining molecules in it. Radical ion hydrated clusters created in such a manner basically contain collective systems of electrons or protons with sufficient energy potential capable of breaking 
bindings between collective electrons of clustered carbon, sulphur and dispersive gold associated with them.

In the course of processing water solution of sodium bicarbonate in electrochemical and photochemical reactors superoxide carboxy-containing compounds $\left(\mathrm{H}_{2} \mathrm{CO}_{4}\right.$ monopercarbonic and $\mathrm{H}_{2} \mathrm{C}_{2} \mathrm{O}_{6}$ percarbonic acids) may be synthesized. Such superoxide compounds are metastable, that's why inside cluster structure they dissociate producing highly active $\mathrm{OH}^{*}$ hydroxyl-radicals (through intermediate phase of hydrogen peroxide extraction): $\mathrm{H}_{2} \mathrm{CO}_{4}=\mathrm{H}_{2} \mathrm{O}_{2}+\mathrm{CO}_{2}, \mathrm{H}_{2} \mathrm{C}_{2} \mathrm{O}_{6}=\mathrm{H}_{2} \mathrm{O}_{2}+2 \mathrm{CO}_{2}, \mathrm{H}_{2} \mathrm{O}_{2}+\mathrm{OH}^{-}=\mathrm{H}_{2} \mathrm{O}+\mathrm{O}^{*-}+\mathrm{OH}^{*}$ or radical ions of hydroxyl and carboxyl-cations - $\left(2 \mathrm{OH}^{*-}+\mathrm{C}_{2} \mathrm{O}_{2}{ }^{+}, 2 \mathrm{OH}^{*-}+\mathrm{C}_{2} \mathrm{O}_{4}{ }^{+}\right)$. Obtained products of dissociation inter-reacting through hydration shells form associates in reverse manner i.e. hydrated clusters with reduced inoculating part - superoxide compounds. Thus, self-oscillations of hydrated clustering - de-clustering, occur in the solution. The reality of such self-oscillations in hydrocarbonate water solutions is proved experimentally during researches conducted in Moscow State University under the guidance of professor, doctor of biological sciences V.L. Voeikova [10]. Therefore, such solutions, or more precisely water-and-gas emulsions retain their activity for relatively long time (tens of hours), while free hydroxyl-radical itself may exist for not more than $10^{-12} \mathrm{~s}$. Due to this the presence of superoxide compounds in leaching solutions will allow keeping them active for sufficient time.

During pre-processing of ore with small (to 3\%) content of sulphide minerals using such activated solutions, clustered dispersive gold with collective electron shells (including hybrid shells, levels 5d-6s) after the oxidation of sulphur bonded chemically with it evolves and may fragmentarily interact with hydroxyl-radical and with atomic hydrogen. Herewith, weakening of bindings between clustered gold atoms may as well occur. It is known that even in natural water there is a stable form of gold $-\mathrm{AuOH}\left(\mathrm{H}_{2} \mathrm{O}\right)^{0}$ at wide $\mathrm{Eh}-\mathrm{pH}$ interval. Therefore, under certain conditions, in mineral environment-process solution system, it becomes possible to perform de-clustering of gold using active hydrated complexes and its relocation in atomic (ionic) form or as part of $\mathrm{AuOH}^{*}, \mathrm{AuH}^{*}$ compounds to the surface of micro-cracks and interstices of concentrating mineral. Subsequently, upon contact with leaching solution, the formation of more stable gold complexes take place with corresponding complexing components directly as well as through the phase of secondary hydrated gold clusters formation.

In the course of preparation of ores containing dispersive gold with higher content of sulphide minerals and arsenopyrite as well as with the presence of carbon black in the amount of $0.1 \%-1 \%$ it is reasonable to use combined preparation including the use of water-and-gas emulsions containing percarbonic acids and sulphuric and peroxide combinations in various linkings and sequence. The oxidation of carbon in sulphuric and peroxide medium occurs by means of its inter-reaction with metastable $\mathrm{H}_{2} \mathrm{~S}_{2} \mathrm{O}_{8}, \mathrm{H}_{2} \mathrm{SO}_{5}$ permonosulphuric and persulphuric acids which may be as well obtained via processing initial solution in electrochemical and photochemical reactors.

In the course of processing refractory ores with obtained water-and-gas emulsions carbon contained in them oxidises to monoxide with metastable permonosulphuric acid by the reaction as follows: $\mathrm{H}_{2} \mathrm{SO}_{5}+\mathrm{C}=\mathrm{H}_{2} \mathrm{SO}_{4}+\mathrm{CO}$

Dispersive gold which retained binding with carbon after the oxidation of the latter forms $\mathrm{Au}-\mathrm{Au}\left(\mathrm{OH}, \mathrm{HCO}_{3}\right)$ complexes by inter-reaction with hydroxyl-radical. 


\section{Materials and research methods}

In order to perform geotechnological assessment of mineral raw materials, experimental studies on gold carbon-bearing argillaceous carbonated ores from one of deposits of Southern Ural were conducted. Prior to leaching, preliminary oxidative preparation of a sample was made by pelletizing ore crushed to fraction of $-5 \mathrm{~mm}+0 \mathrm{~mm}$ with the addition of cement and its watering with photoelectroactive solutions with sulphuric and peroxide and carbonate and peroxide base. Further, pelletized sample weights were being mixed and poured in percolation columns of a bench (fig. 1) as solutions also used after combined oxidation (direct activation chlorination

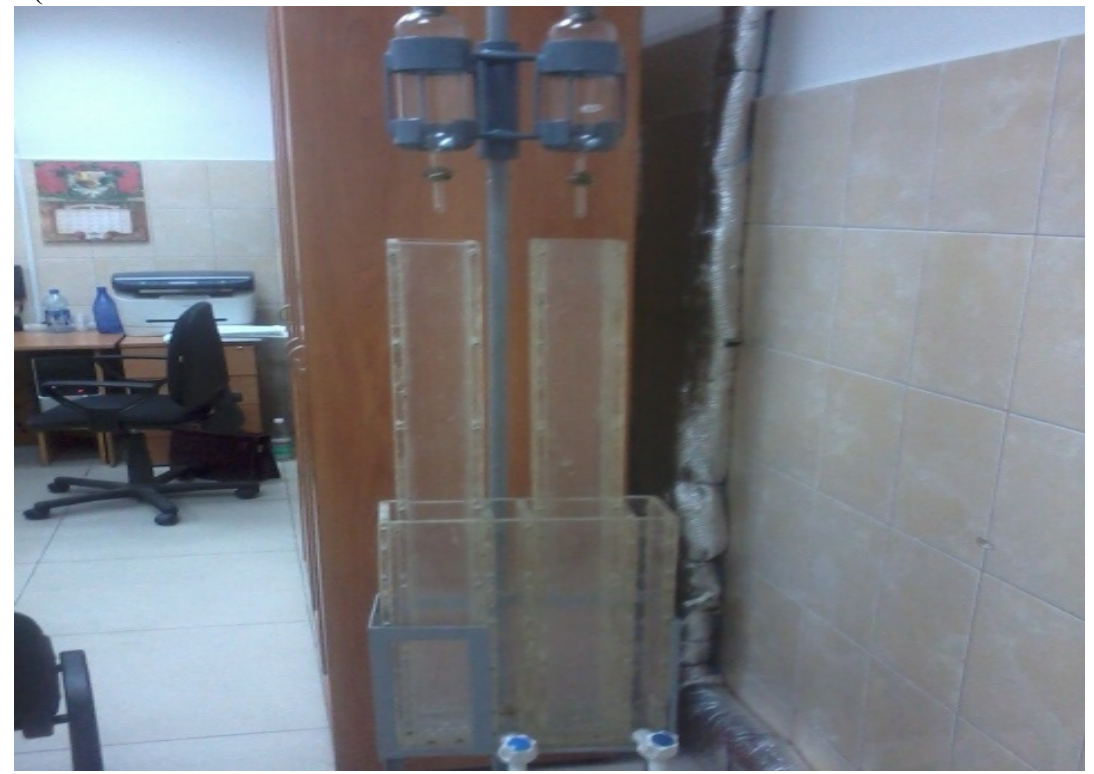

Fig. 1. A bench for geotechnological testing of ores using standard and activation schemes of percolation leaching

1. Watering of pelletized materials with active carbonate and peroxide solution was being performed during 3 days in the first percolator. Three days after it was registered that iron and copper concentration in output solution dropped, $\mathrm{pH}$ rises from 4.8 in first portions of drain solution to 6.8 in the last portions of drain from percolator.

2. Ore sample weights in the second percolator after pelletizing was saturated with the $10 \%$ solution of sodium chloride in amount of $430 \mathrm{ml}$ in order to form hydrochlorideperoxide medium in it after which the second pause of 2.5 days was maintained in order for gold diffusion leaching to occur and carbon-bearing inclusions sorption activity reduction to continue.

3. The watering of ore in the first (reference) percolator was being performed by feeding active alkali cyanic solution with the concentration of $1.5 \mathrm{~g} / 1$ with the flow rate of $300 \mathrm{ml} /$ day.

4. Active chloride solution obtained by photoelectrochemical processing was fed into the second column with the flow rate of $300 \mathrm{ml} /$ day. 


\section{Results and discussion}

Oxidative preparation of ore by pelletizing and its watering with photoelectroactive solutions with sulphuric and peroxide and carbonate and peroxide base enabled essentially increasing gold recovery during subsequent percolation leaching with active chloride $(73.5 \%)$ and cyanic $(55.7 \%)$ solutions what to a significant degree higher than $18 \%$ value of direct cyanation.

\section{Conclusions}

Thus, activation chloride system allows ensuring dispersive gold recovery, associated mainly with sulphur and carbon, suitable for heap leaching.

Besides, the effect of using chloride complexes is as well achieved by the fact that deeper passivation of carbon black at the second main stage of leaching is ensured and accordingly the amount of gold re-precipitated by it from pregnant solutions significantly drops (preg-robbing effect).

Based on experimental findings, in order to realize combined oxidative preparation of carbon-bearing sulphide ore in production, a process scheme given in fig. 2 was developed.

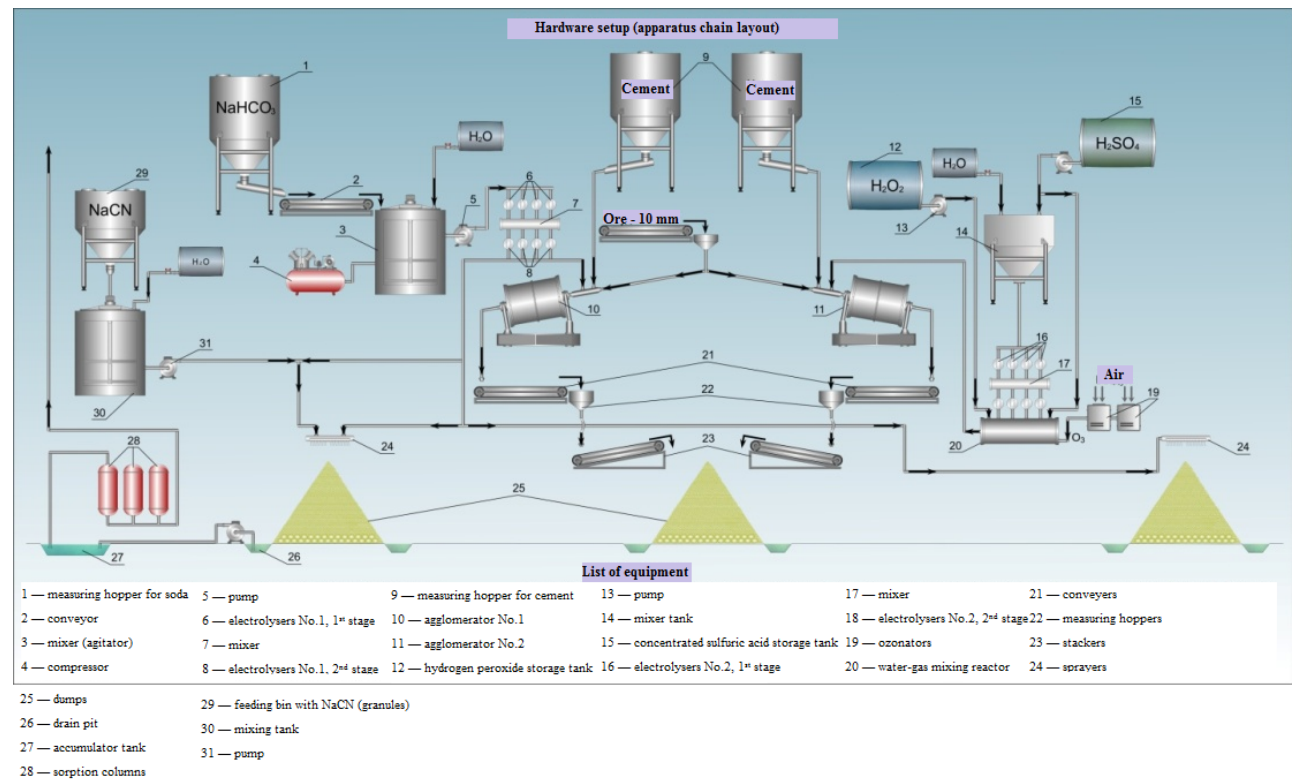

Fig. 2. Scheme for combined oxidation preparation of carbon-bearing sulphide ore with dispersive deportment of gold

The selection of complexing compound option (cyanide or chloride) used after the oxidation of ore from a specific deposit may be determined only based upon feasibility analysis and testing of samples weighing more than 50 tons.

\section{Acknowledgement}

The research was carried out with the support of scientific grant "Development of technology of cyanide-free leaching of refractory gold from low-grade copper and 
porphyritic ores" provided by the Government of Khabarovsk Territory under the contract No. 115/2018D, 28.06.2018.

\section{References}

1. R. K. Amankwah, C. A. Pickles, Min. Eng. 22, pp. 1095-1101 (2009).

2. K.L. Rees, V. Deventer, Hydromet. 58, pp. 61-80 (2000).

3. H. Tan, D. Feng, G.C. Lukey, V. Deventer, Min. Eng. 18, pp. 1361-1372 (2005).

4.

D. D. Gertenbach, Minerals \& Met. Proc. 33, pp. 178-186 (2016).

$5 . \quad$ S. Ubaldini, F. Veglio, L. Toro, C. Abbruzzese, Min. Engineering 13, pp. 1641$1646(2000)$.

6. M. R. Jackson, D. C. Mathewson, S. R. Koehler, W. M. Pennell, L. J. Garside, New Concepts and Discoveries: Geological-Society-of-Nevada's Symposium - New Concepts and Discoveries (2015).

7. M. E. Denisov, B. P. Rudnev, L. N. Krylova, Yu. S. Kuchmina, Nonferrous metallurgy 3, pp. 25-30 (2014).

8. A. G. Sekisov, Y. I. Rubzov, A. Y. Lavrov, J. of Mining Institute 217, pp. 96101 (2016).

9. A. G Sekisov, All-Russian Conference on Challenges for Development in Mining Science and Mining Industry 53 (2017).

10. V. L. Voyeykov http://www.delphis.ru/journal/article/aktivnyi-kislorodorganizovannaya-voda-i-protsessy-zhiznedeelnosti (an electronic source, 2005). 